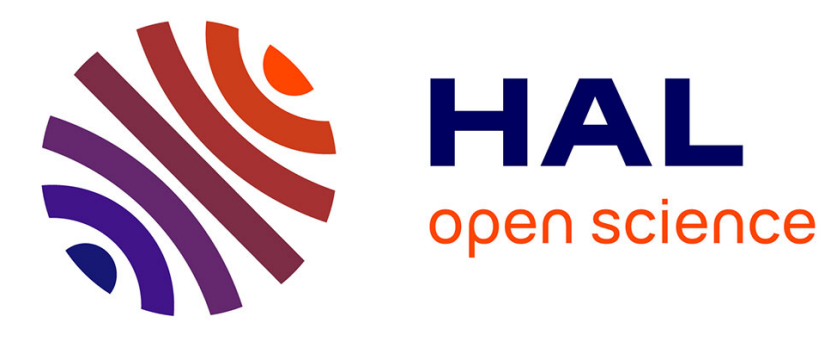

\title{
Impact of Word Presentation for Dyslexia
}

Damien Appert, Philippe Truillet

\section{To cite this version:}

Damien Appert, Philippe Truillet. Impact of Word Presentation for Dyslexia. 18th International ACM SIGACCESS Conference on Computers and Accessibility (ASSETS 2016), Oct 2016, Reno, Nevada, United States. pp. 265-266. hal-01475019

\section{HAL Id: hal-01475019 https://hal.science/hal-01475019}

Submitted on 23 Feb 2017

HAL is a multi-disciplinary open access archive for the deposit and dissemination of scientific research documents, whether they are published or not. The documents may come from teaching and research institutions in France or abroad, or from public or private research centers.
L'archive ouverte pluridisciplinaire HAL, est destinée au dépôt et à la diffusion de documents scientifiques de niveau recherche, publiés ou non, émanant des établissements d'enseignement et de recherche français ou étrangers, des laboratoires publics ou privés. 


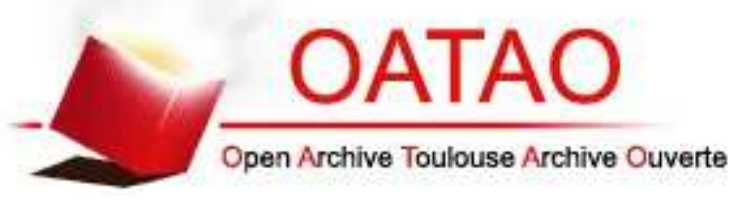

\section{Open Archive TOULOUSE Archive Ouverte (OATAO)}

OATAO is an open access repository that collects the work of Toulouse researchers and makes it freely available over the web where possible.

This is an author-deposited version published in : http://oatao.univ-toulouse.fr/ Eprints ID : 17140

The contribution was presented at ASSETS 2016 :

https://assets16.sigaccess.org/

To cite this version : Appert, Damien and Truillet, Philippe Impact of Word Presentation for Dyslexia. (2016) In: 18th International ACM SIGACCESS

Conference on Computers and Accessibility (ASSETS 2016), 24 October 2016 26 October 2016 (Reno, Nevada, United States).

Any correspondence concerning this service should be sent to the repository administrator: staff-oatao@listes-diff.inp-toulouse.fr 


\section{Impact of Word Presentation for Dyslexia}

\author{
Damien Appert \\ University Toulouse \& CNRS / IRIT \\ Toulouse, France \\ Damien.Appert@irit.fr
}

\author{
Philippe Truillet \\ University Toulouse \& CNRS / IRIT \\ Toulouse, France \\ Philippe.Truillet@irit.fr
}

\begin{abstract}
In this paper, we present an experiment that uses eye-tracking system to measure the effect of word presentation on reading performance and fixation duration. Twelve subjects without dyslexia and eight with dyslexia read thirty-six words and nonwords with three kind of presentation. We show that one type of presentation leads to significant better results for people with dyslexia.
\end{abstract}

\section{Keywords}

Design; experimentation; dyslexia.

\section{INTRODUCTION}

Dyslexics are around $10 \%$ of the population worldwide. Scientific studies [5] have reported difficulties for them with phonological processing, rapid naming, deficits of vision, working memory, processing speed, etc. Regardless, reading problems and spelling difficulties continue to cause concerns, especially in the school system where dyslexic children experience every day the lack of consensual educational instructions regarding their learning problems. The work presented in this paper is related to text presentation. The main contribution is that some visual clues have a significant impact on reading performance for people with dyslexia.

\section{RELATED WORK}

Whereas the phonological deficits seem to be established, the presence and nature of visual impairments is still quite debated. Some authors have shown that dyslexics' eye movements are quite different from those of normal readers: each letter tends to be fixed and there are frequent movements backwards to scan the same letters several times. Many works test the impact of visual perception with eye-tracker systems [7, 8].

Recent findings argue that letter size and crowding do not affect dyslexics and normal readers differently $[3,7]$. Typographic characteristics such as font, type size, spacing between words and letters contrast are all thought to influence legibility in a fashion well known to font designers. Hughes reports an influence of text size on both speed and error [4]. Moreover, having tested subjects on their susceptibility to visual stress, the authors found that children who were susceptible to visual stress performed significantly more poorly when asked to read the smaller texts. Accordingly, the dyslexic community and the websites addressing it recommend a pared down presentation of the information and adapting the reading material. Hence, special fonts for dyslexic have been designed (for example, see Boer, Lexia Readable Gill Dyslexic or Gonzalez works). Rello measured the impact of font type on reading performance [8]. They showed that some font types improved significantly the reading performance. Moreover, we can note that most of the interfaces developed for dyslexics allow a display adaptability.

Gattegno proposed several decades ago a method named "Words in Color" which addressed the problem of learning to read and write [2]. Briefly, it consists of a series of word charts using a color code in which each color represents a phoneme of the language. The charts are used to provoke the phonological awareness in students of the sounds they are making. This work is the basis of the study we conducted with an eye tracker. This served us of playback control tool.

\section{EXPERIMENTAL DESIGN}

The primary purpose of our study is to test the impact of three different word presentation on eye movements for subjects with dyslexia. Can reading process be improved with a color code or semantic code? Are there any interesting visual cues? We defined three types of presentation (see Figure 1): the reference presentation, a "syllabic presentation" where each syllable is separated by a vertical bar -This bar is used as a visual clue- and a "differentiation highlights presentation" where the "d" (colored in cyan) and " $\mathrm{t}$ " (colored in orange) letters are colored relatively to "Words in color" method [2]. These phonemes are close and cause frequent errors in decoding for people with dyslexia.

\section{document do|cu|ment document}

Figure 1. Illustration of three presentations: standard, syllabic and differentiation highlights for the word "document".

We used the Sassoon Sans Bold font in this experiment. This font (see http://www.sassoonfont.co.uk) is a typeface designed with and for children and know to be easily readable.

\section{METHODOLOGY}

\subsection{Design}

The type of presentation and the type of subject (Dyslexics and Non Dyslexics) are our independent variables and we used two dependent variables: The numbers of fixations and the number of read errors. We used the number of fixations as an objective clue of readability. According to Hyönä and al., fixations patterns reflect difficulties in successfully identifying words [5]. We can correlate this variable with reading errors because participants read the texts aloud so we were able to relate oral reading to eye behavior.

The experimental platform is designed from an eye tracker (SMI Eyelink II), PTZ cameras and a microphone to collect the activity of the subjects. We used a 21-inch TFT monitor with a resolution of $1024 \times 768$ pixels. The time measurements of the eye-tracker have a precision of 0.004 second. The subjects were placed at $570 \mathrm{~mm}$ from the screen so that any movement of $1^{\circ}$ angle corresponds to exactly $10 \mathrm{~mm}$ (e.g. 26 pixels) on the screen. 


\subsection{Experimental task}

After reading instructions and calibration phase, subjects began the testing phase This phase consisted of three pre-determined sets of different presentations. Each series consisted of twelve words, chosen pseudo-randomly from the set of thirty-six words in order to balance the non-words and words 3 and 4 syllables. To control the impact of visual cues on word reading strategies, words are placed at the same height, but still shifted (between 1 to $4 \mathrm{~cm}$, randomly) to the right of the screen centre. This configuration requires to perform at least one jerk to be able to read the word. At the end, all subjects read all thirty-six words through three different sets of presentations. The order of presentation was counterbalanced between subjects. Users should read aloud the presented word and repeat it.

\subsection{Results}

The study was conducted with 12 non-dyslexic subjects and 8 dyslexic subjects ( 8 women and 12 men). The ages ranged from 1950 years with an average of 27.3 years. Nobody had mental disabilities and all participants had a good view (no glasses). The subjects first had to pass a preliminary test ("L'Alouette" [6]) to determine their reading level. Note that all dyslexic subjects were recognized as disabled by the $\mathrm{MDPH}^{1}$.

We compute the number of visual fixations for the three of presentations and for dyslexic and non-dyslexic users.

There are more fixations when the user is dyslexic. For dyslexic users, we found a significant effect between types of presentation (Kruskall-Wallis $\chi^{2}=12.90, \quad \mathrm{df}=2, \quad \mathrm{p}<0.01$ ). Moreover, the differentiation highlights and standard presentations are significantly different (Wilcoxon rank sum Pairwise post-hoc $\mathrm{p}<0.02$ ). Compared to the standard form of presentation, our results show an average reduction of $10.8 \%$ of fixings with differentiation highlights form. By cons, we did not find any significant effects between differentiation highlights and standard presentations for non-dyslexic subjects (Kruskall-Wallis $\chi^{2}=14.1, \mathrm{df}=2, \mathrm{p}=\mathrm{n} . \mathrm{s}$.).

This is why we focused thereafter only with results from standard and differentiation highlights layout. The next question was whether this result could be correlated with improved playback performance aloud. As we recorded the words read, we could compare with them with presentation type.

For the standard presentation, there is a significant effect of the number of visual fixations between dyslexic and non-dyslexic subjects (Kruskall-Wallis $\chi^{2}=59.95, \mathrm{df}=1, \mathrm{p}<0.001$ the number of words read correctly (Kruskall-Wallis $\chi^{2}=5.29$, $\mathrm{df}=1, \mathrm{p}<0.03$ ).

Regarding the differentiation highlights presentation, we also found a significant effect on the number of visual fixations between dyslexic and non-dyslexic subjects (Kruskall-Wallis $\chi^{2}=33.69$, $\mathrm{df}=1, \mathrm{p}<0.001)$. However, there is no significant effect on the words read correctly (Kruskall-Wallis $\chi^{2}=1.13, \mathrm{df}=1, \mathrm{p}=$ n.s.). Actually, it seems that the differentiation highlights presentation reduces reading errors. The performance of dyslexic subjects approaches the performance of normal-readers. Finally, it should be noted that this presentation does not affect the performance of normal-readers.

\section{DISCUSSION}

Actually, it seems that the differentiation highlights presentation can greatly reduce reading errors. Moreover, the performance of dyslexic users approaches the performance of non-dyslexic users.
It may be argued that our results obtained using a reading aloud task would not necessarily generalize to silent reading. However, we can argue (as for [5]) that in oral reading, eye movements are closely linked with word recognition processes.

Our results on reading and spelling performances provide evidence that word presentation have an impact for dyslexic readers. These results are consistent with many researches on text design recommendations for people with dyslexia $[1,8,9]$. Nevertheless, these studies focus mainly on fonts or document structure, but few on word or text salience. This could be interesting to link this result to neuroscience studies. Does the salience layout allow to "see" in a better way and understand what is written? Is it more effective than cutting words into syllables for example?

\section{CONCLUSION AND FUTURE WORK}

The main conclusion of this preliminary work is that the "differentiation highlights" presentation has an impact both on number of fixations for dyslexic users and on readability. These findings can guide some analysis, design and evaluation of reading interfaces for Dyslexics. We currently integrate this work on an interface in order to evaluated this work with more complex texts in a natural interaction.

\section{REFERENCES}

[1] French M., Blood A., Bright N. D., Futak D.; Grohmann M. J., Hasthorpe A., Heritage J., Poland R., Reece S., Tabor J. Changing Font in Education: How the benefits vary with ability and dyslexia, The Journal of Educational Research, 106:301-304, 2013

[2] Gattegno C., Teaching Reading with Words in Color: A Scientific Study of the Problems of Reading, Educational Solutions, 1967-2011

[3] Gregor P., Newell A., An empirical investigation of ways in which some of the problems encountered by some dyslexics may be alleviated using computer techniques, ASSETS'00, pp. 85-91

[4] Hughes, L.E. \& Wilkins, A.J. 2000, Typography in children's reading schemes may be suboptimal: Evidence from measures of reading rate. Journal of Research in Reading, 23(3), pp. 314-324.

[5] Hyönä J., Olson R. K., Eye Fixation Patterns Among Dyslexic and Normal Readers: Effects of Word Length and Word Frequency, Journal of Experimental Psychology, Learning, Memory and Cognition, 1995, vol.21 nº, pp. $1430-1440$

[6] Lefavrais P., Description, définition et mesure de la dyslexie, Utilsiation du test «L'Alouette ». Revue de Psychologie Appliquée, 15 (1), pp. 33-44, 1965

[7] MacKeben M, Trauzettel-Klosinski S, Reinhard J, Dürrwächter U, Adler M, Klosinski G., Eye movement control during single-word reading in dyslexics, Journal of Vision, 2004 May 14;4(5): pp. 388-402.

[8] Rello L, Baeza-Yates R., Good Fonts for Dyslexia, ASSETS'13, October 21-23 2013, pp. 14-22

[9] Rello L., Baeza-Yates R., How to Present more Readable Text for People with Dyslexia, Univ Access Inf Soc (2015). doi:10.1007/s10209-015-0438-8 